\title{
Neuropsychological consequences of volatile substance abuse: a population based study of secondary school pupils
}

\author{
Oliver Chadwick, Ross Anderson, Martin Bland, John Ramsey
}

\begin{abstract}
Objective-To examine the effects of volatile substance abuse on neuropsychological functioning.

Design-A sample of index children and matched controls were identified by a two stage procedure. Firstly, over 5000 secondary school pupils completed a screening questionnaire, and, secondly, a sample of those who acknowledged volatile substance abuse and a matched sample of those who denied the practice were assessed in detail by means of $(a)$ individually conducted interviews and (b) toxicological examination of breath samples (to exclude those intoxicated at the time of testing).

Setting-16 Local education authority secondary schools in London.
\end{abstract}

Subjects - 160 Pupils aged 13-16: 80 index children who had abused volatile substances to the point of intoxication at least once (confirmed by interview) and 80 controls (confirmed by interview) matched for school year, sex, and ethnic background.

Measurements and main results-Neuropsychological functioning tests provided $\mathbf{3 5}$ main outcome measures and were administered blind. Data on educational test performance before substance abuse began were obtained retrospectively. Information on potentially confounding social factors, such as number of siblings, tenure of housing, and parents' socioeconomic and employment state was also obtained. The index children performed significantly less well than the controls in tests of vocabulary, verbal intelligence quotient, full scale intelligence quotient, and a measure of impulsivity. When background social disadvantage was taken into account these differences were no longer significant. There were no significant associations between performance on psychological testing and frequency of abuse, and relations with other aspects of the children's history of abuse were generally weak or unsystematic. Comparisons between the results of these tests and of educational tests taken before substance abuse produced equivocal findings.

Conclusion-Volatile substance abuse, as commonly practised by secondary school pupils, is unlikely to result in neuropsychological impairment.

\section{Introduction}

The practice of deliberately inhaling solvents or other volatile substances is widespread among young people,$^{1-3}$ and concern has often been expressed about its potential dangers. Because these substances are preferentially absorbed into organs with high lipid concentrations a particular concern has been possible damage to the brain. Immediate and short term neuropsychological effects of inhaling solvents have been clearly shown both in laboratory studies of experimentally exposed volunteers and in field studies of people routinely exposed to solvents at work. ${ }^{+5}$ Less is known about the long term effects. Moreover, whether the findings from studies of people exposed at work (who are usually exposed to fairly low con- centrations for prolonged periods of time) can be applied to volatile substance abusers (who typically experience fairly brief exposures to very high concentrations) is uncertain.

Long term abuse of some volatile substances may result in neurological and neuropsychological damage ${ }^{6-9}$ All of this evidence, however, has come from studies concerned primarily with young adults who have abused volatile substances frequently (usually daily) and over prolonged periods (typically for several years). Little is known about the risks among young people who abuse these substances less frequently even though such cases are far more numerous than habitual abusers. Surveys of secondary school pupils in both the United Kingdom and the United States have consistently indicated that most of those who abuse volatile substances do so only occasionally and that only a small minority persist with the practice to become long term or habitual users. $^{2310-12}$

We examined the risk of neuropsychological impairment due to volatile substance abuse at frequencies prevalent among secondary school pupils. We used a population based survey to provide a sampling frame for selecting index children and controls, and the neuropsychological state of these two groups was then compared.

\section{Subjects and methods} POPULATION SCREENING

Children who had abused volatile substances were provisionally identifled from self completed screening questionnaires that were given to pupils aged 13-16 at 16 local education authority secondary schools in three adjacent areas: one division of the Inner London Education Authority (five schools) and two outer London boroughs (11 schools). The questionnaire had been developed and piloted in four schools in another borough.

At each school a letter was sent to the parents of each child explaining the study and giving them the opportunity to withdraw their child. Pupils whose parents refused permission and those who declined to participate were excluded from the study. The questionnaire was given to the pupils in their usual classrooms and was introduced, distributed, and collected by a member of the research team. It took .15-25 minutes to complete and consisted of 31 questions about the child's age, sex, domestic circumstances, general and respiratory health, history of cigarette smoking, volatile substance abuse, alcohol consumption, current behavioural and emotional problems, and physical exercise habits. The confidentiality of the pupils' responses was emphasised, and teachers were openly encouraged to leave the classroom as soon as the class had settled. The pupils were asked to record their date of birth and school class so that those selected for further assessment and follow up could be identified later from the school register.

A total of 7485 pupils were eligible for inclusion in the survey: 825 of them $(11.0 \%)$ were excluded at the 
request of their parents and $1180(15 \cdot 8 \%)$ were absent when the questionnaire was given out. Completed questionnaires were obtained from 5014 pupils, of whom $208(4 \cdot 1 \%)$ indicated that they had at some time abused volatile substances to the point of intoxication.

\section{INDIVIDUAL ASSESSMENTS}

At each school a sample of those who acknowledged that they had deliberately "sniffed glue or solvents (or anything else)" to the point of intoxication were selected for individual assessment. At schools where the questionnaire yield was high those who had abused volatile substances most frequently were examined first to ensure that as many heavy abusers as possible were tested in the time available. For each index child a control who had denied abuse on the questionnaire was also selected for individual assessment. The controls were selected at random from the same schools and from the same sex and school year as the index children. The individual assessments took place at the schools as soon as possible after the questionnaire had been given, usually on the next school day. They consisted of a short interview, a breath test, and an extensive battery of psychological tests.

\section{Interview}

The purpose of the interview was to check the validity of the child's answers on the questionnaire, to obtain detailed information on the frequency and pattern of volatile substance abuse, and to collect information on background sociodemographic and other factors that might be expected to affect performance in psychological tests. The interviews were conducted without knowledge of the child's answers on the questionnaire. A standard format was followed, but the interviewers were encouraged to supplement the basic schedule to set the child at ease, promote confidence, and thereby increase the likelihood of obtaining valid and truthful information. A total of 133 children who had responded positively on the questionnaire were interviewed, and volatile substance abuse was confirmed by $106(79.7 \%)$ of them. A total of 106 children who had responded negatively on the questionnaire were also interviewed, and all of them confirmed that they had not abused volatile substances. The samples therefore consisted of 106 pairs. At interview, however, 25 pairs were found to be unmatched for ethnic background, and these children were omitted from their respective samples, thereby reducing the sample size to 81 pairs.

\section{Toxicological examination of breath samples}

The breath test identified children who might have been under the influence of volatile substances (or alcohol) at the time of psychological testing. Breath samples were analysed with a modified personnel and trace gas analyser (VG Instruments, Cheshire), which uses mass spectrometry to detect and identify traces of volatile compounds in exhaled air. The presence of alcohol was tested for with an infrared analyser (Camic, Northumberland) but was not detected in the breath of any child.

Seven index children and one control were positive for volatile substances. In the seven index children the substances identified were consistent with the product that was reported to have been abused most recently (1,1,1-trichloroethane in six children who had last abused typewriter correction fluids and toluene in one child who had most recently abused petrol). These seven children were kept in the sample pending examination of the effect of their removal on the results of the neuropsychological tests. The control was positive for toluene (for reasons that could not be satisfactorily explained). He was excluded from the study (as was the index child with whom he was matched), thereby reducing the sample size to 80 matched pairs.

\section{Neuropsychological tests}

The battery of neuropsychological tests was designed to assess a range of functions that had been implicated in previous studies of $(a)$ long term volatile substance abuse or occupational exposure to solvents and $(b)$ other exposures of the central nervous system, such as alcohol abuse in adults and severe head injury or meningitis in children and adolescents. The tests took about one and a half hours to complete and were given without knowledge of the child's responses to the questionnaire or at interview or the toxicological findings.

Wechsler intelligence scale for children ${ }^{13}-$ The similarities, vocabulary, picture completion, and block design subtests were used.

Reading test $\mathrm{EH}-3^{14}-\mathrm{A}$ test of reading comprehension speed.

Logical memory ${ }^{15}$-Immediate and delayed recall after 45 minutes.

Speed of information processing (version $E$ ) from the British ability scales. ${ }^{16}$

${ }^{\star}$ Bexley-Maudsley automated psychological screening test $^{17}$ comprised $(a)$ visual perceptual analysis (a simultaneous visual matching task) and (b) symboldigit coding test (a computerised adaptation of the Digit symbol subtest).

${ }^{\star}$ Automated psychological test system (A Elithorn and S Levander, unpublished)-(1) Three forms of reaction time task were used: $(a)$ simple unprepared visual reaction time; $(b)$ two choice visual reaction time; and $(c)$ "inhibitory" two choice visual reaction time. Test $(c)$ was similar to test $(b)$ except that in half of the trials a tone was presented at the same time as the visual stimulus and in these trials the subject was required to withhold the response. (2) Finger tapping tasks ${ }^{\star}$ were performed. The number of times a key was pressed on a special response console in eight seconds with $(a)$ right index finger; $(b)$ left index finger; $(c)$ right index and middle fingers alternating; $(d)$ left index and middle fingers alternating; $(e)$ right and left index fingers alternating. (3) A trail-making task ${ }^{\star}$ was assessed. This was an automated version of the test,${ }^{18}$ in which a joystick on the response console was used to move the monitor cursor to "hit" the target items.

Manual dexterity task. ${ }^{19}$

Vibration perception threshold measurement ${ }^{20}-\mathrm{A}$ biothesiometer - a hand held mains operated device with a $100 \mathrm{~Hz}$ vibrating rubber tactor (Bio-Medical Instrument $\mathrm{Co}$, Newbury, Ohio) - was applied at right angles to the palmar aspect of the thumb opposite the nail bed and to the medial malleolus of the subject's non-preferred thumb or leg. The amplitude of vibration was gradually increased from zero until the subject reported feeling it. The threshold of perception was taken as the median of three trials at each site.

EDUCATIONAL ATTAINMENT ANTECEDENT TO VOLATILE SUBSTANCE ABUSE

The schools were asked to provide the results of any standardised educational tests that had been taken by the index children and controls at the time of transfer from primary to secondary school. For the index children the date when the test was taken was compared with the date at which the child had started to abuse volatile substances (as determined at interview) to ensure that the test had indeed been taken before the first episode of abuse.

Valid data came from tests of reading ability (Neale analysis of reading ability, Schonell word reading test, Holborn reading test, London reading test, or Burt word reading test) or verbal reasoning tests (National ^Indicates tests carried out with Apple IIe microcomputer. 
Foundation for Educational Research verbal reasoning tests, cognitive abilities test (verbal reasoning quotient), and the Moray house verbal reasoning tests). For most tests the data came in the form of an age standardised quotient with a mean of 100 and a standard deviation of 15 , but for the Neale, Schonell, and Holborn reading tests the scores came in the form of a reading age (in years and months). To convert these scores to the same metric the reading ages were transformed into equivalent scores on the London reading test (form $\mathrm{A}$ ) with the empirical data collected to validate the test ${ }^{21}$ and then converted into standardised quotients.

\section{STATISTICAL METHODS}

The significance of differences between index children and controls on categorical variables (see table I) was examined by $\chi^{2}$ tests; differences in mean psychological test scores were examined with $t$ tests for matched samples (see tables V and VI). For a few of the test measures - for example, those indicating the number of errors made in the test-the distribution of the scores of each group seemed to be skewed. By examining the differences between the scores of the index children and controls, however, this skew was reduced, and because of the large sample size approximation to the normal distribution was reasonably good. The sample size of 80 pairs gave an $80 \%$ chance of detecting a difference between groups of $0.6 \mathrm{SD}$ and a $90 \%$ chance of detecting a difference of $0.7 \mathrm{SD}$. The effect of frequency of abuse and other factors relating to a history of abuse (see table V) were examined by analysis of variance of the differenct scores of each subgroup.

ETHICAL APPROVAL

The study was approved by the ethical committee of the local district health authority.

\section{Results}

COMPARABILITY OF THE TWO GROUPS

The two groups were identical in terms of the distributions of school year, sex, and ethnic background and closely comparable in terms of mean age. Seventy two $(90 \%)$ of the pairs were also matched for school, but for various practical reasons the remaining eight pairs came from different schools. The background domestic circumstances of the index children were generally less favourable than those of the controls. They were significantly more likely to have three or more siblings, to come from families living in rented accommodation, and to come from homes in which neither parent was employed $(p<0.05)$ (table I).

TABLE I-Background sociodemographic and domestic circumstances of index children and controls questioned on volatile substance abuse. Figures are numbers of children unless stated otherwise

\begin{tabular}{|c|c|c|}
\hline & $\begin{array}{c}\text { Controls } \\
(\mathbf{n}=80)\end{array}$ & $\begin{array}{l}\text { Index children } \\
\quad(\mathrm{n}=80)\end{array}$ \\
\hline Mean (SD) age (months) & $179 \cdot 5(9 \cdot 4)$ & $180 \cdot 5(8 \cdot 6)$ \\
\hline \multicolumn{3}{|l|}{ Age (years): } \\
\hline 13 & 14 & 7 \\
\hline 14 & 25 & 31 \\
\hline 15 & 35 & 35 \\
\hline 16 & 6 & 7 \\
\hline Boys & 36 & 36 \\
\hline Girls & 44 & 44 \\
\hline Not living with both natural parents ${ }^{\star}$ & 24 & 31 \\
\hline$\geqslant 3$ Siblingst & 18 & $33 \ddagger$ \\
\hline Accommodation owned by family or family paying mortgage & 51 & $38 \ddagger$ \\
\hline \multicolumn{3}{|l|}{ Occupational state of head of householdt: } \\
\hline I, II, III Non-manual & 27 & 18 \\
\hline III Manual & 32 & 34 \\
\hline IV, V & 15 & 12 \\
\hline Head of household unemployed $t$ & 2 & $9 \ddagger$ \\
\hline
\end{tabular}

^Data from questionnaire.

†Data from interview.

$\neq \mathrm{p}<0 \cdot 05$.
TABLE II-Frequency of volatile substance abuse among screened and index children

\begin{tabular}{lcc}
\hline Frequency of abuse & $\begin{array}{c}\text { No (\%) who } \\
\text { responded positively } \\
\text { to questionnaire } \\
(\mathrm{n}=195)\end{array}$ & $\begin{array}{c}\text { No }(\%) \text { of } \\
\text { index } \\
\text { childrent } \\
(\mathrm{n}=78)\end{array}$ \\
\hline Once or twice & $92(47)$ & $27(35)$ \\
Three or four times & $27(14)$ & $11(14)$ \\
5-9 Times & $32(16)$ & $11(14)$ \\
10-30 Times & $26(13)$ & $15(19)$ \\
?30 Times & $18(9)$ & $14(18)$
\end{tabular}

^Not known for 13 children who responded positively to questionnaire and two index children.

tInterview response.

TABLE III - Products abused by 80 index children

\begin{tabular}{lc}
\hline \multicolumn{1}{c}{ Product } & No of children \\
\hline Typewriter correcting fluid & 63 \\
Glue & 24 \\
Gas lighter fuel/butane gas & 20 \\
Dry cleaning fluids/degreasing agents & 7 \\
Amyl nitrite & 4 \\
Petrol & 2 \\
Paint stripper & 2 \\
Aerosols & 1 \\
Paraffin & 1
\end{tabular}

TABLE IV-Time since initial and most recent episodes of volatile substance abuse among index children ${ }^{\star}$

\begin{tabular}{lcc}
\hline Time since abuse & Initial episode & Most recent episode \\
\hline <1 Week & & 6 \\
1 Week-1 month & 1 & 9 \\
>1-6 Months & 18 & 26 \\
>6-12 Months & 20 & 22 \\
>1-2 Years & 16 & 9 \\
> Years & 12 & 6 \\
Not known & 13 & 2 \\
\hline
\end{tabular}

^Interview responses.

\section{FREQUENCY AND PATTERN OF VOLATILE SUBSTANCE} ABUSE

By design the proportion of frequent volatile substance abusers was somewhat higher among the index children whose abuse was confirmed at interview than among the total sample identified by means of the questionnaire. Even so about a third of the index children reported at interview that they had abused only once or twice, and less than one in five had abused more than 30 times (table II). Finer gradation of the frequency of abuse in this second group was not possible because many of them found it difficult to estimate just how often they had abused.

Most $(63 \%)$ of the index children whose abuse was confirmed at interview had abused only one product, but a third had abused two or three different products, and three of the 80 children acknowledged having abused more than three different products. Typewriter correction fluid or "thinner" was the most popularly abused product, having been tried by about three quarters of the children. Various glues had been abused by nearly a third and butane gas by a quarter of them. Other substances had been abused by a much smaller proportion of the children (table III).

About half of the index children whose abuse was confirmed at interview could be described as "current sniffers," inasmuch as they had abused volatile substances within the six months before the interview. Many of them, however, had a fairly short history of abuse: more than $80 \%$ had first sniffed during the two years before the interview and over half had first abused during the preceding 12 months (table IV).

\section{NEUROPSYCHOLOGICAL TEST RESULTS}

The index children performed significantly less well $(p<0.05)$ than their matched controls on just four of 
the 35 neuropsychological outcome measures that were examined. Three of these-vocabulary, prorated verbal intelligence quotient, and prorated full scale intelligence quotient - were from the Wechsler scales. The fourth was the "inhibitory" version of the reaction time task, on which the index children failed to withhold inappropriate responses more often than the controls (table V). These four measures continued to show a significant difference between groups after the seven index children who yielded a positive result on breath testing (and their matched controls) had been excluded from the sample.

To identify potentially confounding social factors that might account for these findings each of the five background social variables shown in table I was examined in relation to the test results of the index children and controls. Three variables - number of siblings, parental socioeconomic state, and tenure of housing-showed a relation with performance in psychological tests that was considered strong enough and sufficiently independent of the relation with the two others to warrant taking their effects into account. Multiple regression analyses with these three factors added into the equation showed no significant differences between the groups on the four measures that had previously shown a difference. A significant difference between index children and controls was found on one other measure: the index children made significantly more left/right errors in the two choice reaction time test $(\mathbf{p}<0.05)$, but as this difference had not emerged in the previous uncontrolled analysis and

TABLE V-Mean (SD) results of psychological tests

\begin{tabular}{|c|c|c|}
\hline & $\begin{array}{l}\text { Controls } \\
(\mathrm{n}=80)\end{array}$ & $\begin{array}{l}\text { Index children } \\
\quad(\mathbf{n}=80)\end{array}$ \\
\hline \multicolumn{3}{|l|}{ Weschler intelligence scale for children (revised): } \\
\hline Similarities & $12 \cdot 0(3 \cdot 3)$ & $11 \cdot 1(3 \cdot 2)$ \\
\hline Vocabulary & $10 \cdot 2(2 \cdot 5)$ & $9 \cdot 4(2 \cdot 3)^{\star}$ \\
\hline Picture completion & $10 \cdot 4(2 \cdot 6)$ & $10 \cdot 1(2 \cdot 8)$ \\
\hline Block designt & $12 \cdot 1(2 \cdot 8)$ & $11 \cdot 4(2 \cdot 2)$ \\
\hline Verbal intelligence quotient (prorated) & $106 \cdot 9(16 \cdot 7)$ & $101 \cdot 3(14 \cdot 7)^{\star}$ \\
\hline Performance intelligence quotient (prorated) $\dagger$ & $109 \cdot 0(14 \cdot 6)$ & $105 \cdot 2(14 \cdot 3)$ \\
\hline Full scale intelligence quotient (prorated) & $108 \cdot 8(15 \cdot 1)$ & $103 \cdot 4(14 \cdot 3)^{\star}$ \\
\hline Reading quotient & $103 \cdot 9(12 \cdot 4)$ & $102 \cdot 0(13 \cdot 1)$ \\
\hline \multicolumn{3}{|l|}{ Passage recall (items recalled): } \\
\hline Immediate presentation & $10 \cdot 5(3 \cdot 8)$ & $9 \cdot 6(3 \cdot 3)$ \\
\hline Delayed presentation & $10 \cdot 1(3 \cdot 7)$ & $9 \cdot 0(3 \cdot 5)$ \\
\hline Speed of information processing ( $\mathrm{T}$ score) & $52 \cdot 3(8 \cdot 1)$ & $50 \cdot 5(7 \cdot 0)$ \\
\hline \multicolumn{3}{|l|}{ Manual dexterity: } \\
\hline Right hand (s) & $10 \cdot 2(1 \cdot 1)$ & $10 \cdot 2(1 \cdot 0)$ \\
\hline Left hand $(\mathrm{s})$ & $11 \cdot 0(1 \cdot 2)$ & $11 \cdot 0(1 \cdot 4)$ \\
\hline \multicolumn{3}{|l|}{ Vibration sensation threshold: } \\
\hline Thumb & $3 \cdot 2(1 \cdot 8)$ & $3 \cdot 2(1 \cdot 2)$ \\
\hline Ankleł & $7 \cdot 3(4 \cdot 6)$ & $7 \cdot 1(2 \cdot 1)$ \\
\hline \multicolumn{3}{|l|}{ Bexley-Maudsley automated tests: } \\
\hline \multicolumn{3}{|l|}{ Visual perceptual analysis: } \\
\hline Reaction time: & . & \\
\hline Difficult items & $5 \cdot 4(1 \cdot 3)$ & $5 \cdot 7(1 \cdot 8)$ \\
\hline Easy items & $3 \cdot 9(1 \cdot 1)$ & $4 \cdot 0(1 \cdot 1)$ \\
\hline \multicolumn{3}{|l|}{ Errors: } \\
\hline Difficult items & $0 \cdot 7(1 \cdot 2)$ & $1 \cdot 0(1 \cdot 5)$ \\
\hline Easy items $₫$ & $0.4(0.9)$ & $0.5(0.9)$ \\
\hline \multicolumn{3}{|l|}{ Symbol-digit coding: } \\
\hline \multicolumn{3}{|l|}{ Reaction time: } \\
\hline First 15 & $1.95(0 \cdot 29)$ & $2 \cdot 02(0.35)$ \\
\hline Second 15 & $1.85(0.30)$ & $1.93(0.37)$ \\
\hline Third 15 & $1 \cdot 80(0 \cdot 28)$ & $1.85(0.32)$ \\
\hline All 45 & $1 \cdot 86(0 \cdot 25)$ & $1.94(0.31)$ \\
\hline Mistakes: all 45 & $1.0(1.5)$ & $1 \cdot 0(1 \cdot 5)$ \\
\hline \multicolumn{3}{|l|}{ Reaction time tests: } \\
\hline \multicolumn{3}{|l|}{ Two choice: } \\
\hline Reaction time: either hand $₫$ & $0.364(0.073)$ & $0.373(0.084)$ \\
\hline Left-right errors $\dagger$ & $2 \cdot 1(1 \cdot 1)$ & $2 \cdot 3(2 \cdot 2)$ \\
\hline \multicolumn{3}{|l|}{ Two choice with inhibition: } \\
\hline Reaction time: either hand & $0.561(0 \cdot 121)$ & $0.595(0.148)$ \\
\hline Failed inhibitory responses & $1 \cdot 2(1 \cdot 3)$ & $1.9(2 \cdot 0)^{\star}$ \\
\hline \multicolumn{3}{|l|}{ Finger tapping (taps/s): } \\
\hline Right hand indext5 & $5 \cdot 8(1.4)$ & $6 \cdot 1(1 \cdot 7)$ \\
\hline Left hand index & $5 \cdot 3(1 \cdot 1)$ & $5 \cdot 0(1 \cdot 2)$ \\
\hline Right hand index/middle $\$$ & $2 \cdot 5(0 \cdot 8)$ & $2.5(0.9)$ \\
\hline Left hand index/middle & $2 \cdot 2(0 \cdot 7)$ & $2 \cdot 3(0.7)$ \\
\hline Right/left hand index & $3.4(0.8)$ & $3.7(1.0)$ \\
\hline \multicolumn{3}{|l|}{ Trail making (s/target): } \\
\hline A & $2 \cdot 5(1 \cdot 0)$ & $2 \cdot 3(0 \cdot 5)$ \\
\hline B & $3 \cdot 2(0.9)$ & $3 \cdot 1(0 \cdot 6)$ \\
\hline
\end{tabular}

${ }^{\star} \mathrm{p}<0.05$.

$\mathrm{p}<0.05$ For relation to:

ftime since last abuse; $\quad$ łnumber of different products abused; Stime since first abused.
TABLE VI-Mean (SD) results of psychological tests before and after children began to abuse volatile substances

\begin{tabular}{|c|c|c|c|}
\hline & $\begin{array}{l}\text { Test scores } \\
\text { before abuse }\end{array}$ & $\begin{array}{l}\text { Test scores } \\
\text { after abuse }\end{array}$ & $\begin{array}{l}\text { Change } \\
\text { over time }\end{array}$ \\
\hline \multicolumn{4}{|c|}{ Reading ability } \\
\hline $\begin{array}{l}\text { Controls }(n=19) \\
\text { Index children }(n=19)\end{array}$ & $\begin{array}{l}103 \cdot 5(11 \cdot 2) \\
103 \cdot 1(13 \cdot 0)\end{array}$ & $\begin{array}{l}106 \cdot 6(15 \cdot 2) \\
100 \cdot 3(13 \cdot 0)\end{array}$ & $\begin{array}{r}3 \cdot 1 \\
-2 \cdot 8\end{array}$ \\
\hline \multicolumn{4}{|c|}{ Verbal reasoning or verbal intelligence quotient $\dagger$} \\
\hline $\begin{array}{l}\text { Controls }(n=21) \\
\text { Index children }(n=21)\end{array}$ & $\begin{array}{l}104 \cdot 3(12 \cdot 4) \\
110 \cdot 6(10 \cdot 9)\end{array}$ & $\begin{array}{l}107 \cdot 6(16 \cdot 2) \\
105 \cdot 6(17 \cdot 0)\end{array}$ & $\begin{array}{c}3 \cdot 3^{\star} \\
-5 \cdot 0\end{array}$ \\
\hline
\end{tabular}

${ }^{\star} \mathrm{p}<0.05$.

${ }^{\star} \mathrm{p}<0.05$.
+ Verbal reasoning quotient before abuse; verbal intelligence quotient after abuse.

as it was just one of 35 significance tests that were carried out its significance must be regarded with caution.

There were no significant effects of frequency of abuse on any of the outcome measures, either when frequency of abuse was categorised into five subgroups (see table II) or when the five subgroups were collapsed into three (once or twice, 3-9 times, and $\geqslant 10$ times).

Examination of the results of the psychological tests in relation to the time since volatile substances were last abused, the number of different types of product abused, and the time since volatile substances were first abused showed significant effects on only a few isolated measures (see table V). Inspection of the mean subgroup scores, however, indicated that all but one of these significant relations seemed to be either unsystematic or inconsistent with the hypothesis of a detrimental effect of volatile substance abuse. The only exception to this was the relation between the time since the child had first abused and the number of errors on the simple version of the visual discrimination task. The longer the time since children had first abused, the more errors they made compared with the controls.

Comparison of the effects of abusing different types of product was not possible because three quarters of the index children who had abused only one type of product had abused typewriter correction fluids, and the number who had abused only other substances was too small to warrant analysis of the findings.

We tried to examine the subsidiary hypothesis that exposure to volatile substances results primarily in variability of behaviour rather than a decrease in performance. ${ }^{22}$ The standard deviation of each subject's mean reaction time on each of the eight reaction time measures was calculated and the mean standard deviation of the two groups compared. Only one of these eight measures showed a significant difference between groups: the index children showed greater variability of reaction times when correctly responding on the inhibitory version of the two choice reaction time task $(\mathrm{p}<0 \cdot 05)$.

Results of educational tests taken at the time of transfer from primary to secondary school were obtained for 56 index children and 62 controls, of whom 40 were matched pairs. Antecedent scores of reading tests were compared with scores on the reading test given during the study; scores of antecedent verbal reasoning tests were compared with prorated verbal intelligence quotients. Table VI gives the results. Relative to their test scores before abuse, the verbal reasoning scores of the index children were lower by 5.0 points on average, whereas those of their matched controls were increased by 3.3 points $(p<0 \cdot 05)$. The antecedent test scores of the index children, however, were 6.3 points higher than those of the controls and their subsequent test scores not significantly different. Longitudinal comparison of the reading test scores of the two groups also indicated an improvement in 
the performance of the controls and a fall in the performance of the index children, though this difference was not significant.

\section{Discussion}

This study attempted to overcome the methodological shortcomings of previous research on the neuropsychological consequences of volatile substance abuse $^{9}$ by ensuring that $(a)$ sample sizes were adequate; (b) the index children and controls were comparable in terms of factors, other than volatile substance abuse, that might affect test performance; $(c)$ the index children were not under the short term influence of volatile substances at the time of psychological testing; (d) testing was carried out blind to whether the subject was an index child or control; and $(e)$ data from tests before abuse began were obtained to allow before and after comparisons.

Our findings indicate that children with a history of volatile substance abuse typical of that found among 13-16 year old secondary school children in the study area were impaired on tests of vocabulary, verbal intelligence quotient, and full scale intelligence quotient. They were also more likely to make impulsive errors and to perform more erratically than other children of the same age on a task that required them to withhold a response. The pattern of findings among the index children was reminiscent of that found among heterogeneous groups of young people with behavioural problems. Generally, juvenile delinquents and hyperactive children show only a mild degree of intellectual impairment, the deficit in verbal intelligence quotient usually being slightly greater than the deficit in performance intelligence quotient. ${ }^{23}$ They tend to make impulsive errors ${ }^{24}$ and are more likely to come from disadvantaged and disorganised homes.

Intellectual impairment and disinhibition are also recognised results of damage to the central nervous system, ${ }^{26}$ but several findings from our study suggest that the observed deficits are unlikely to reflect a causal effect of volatile substance abuse on neuropsychological functioning. Firstly, when the differences between the groups in background domestic circumstances were taken into account the previously observed differences in performance in psychological tests were no longer significant. Secondly, there was no evidence of a dose-response relation between frequency of abuse and the magnitude of the deficit on psychological testing. Similarly, the relations between test scores and other aspects of the child's history of abuse were generally weak or unsystematic. Thirdly, the pattern of deficits observed, with greater impairment in the verbal subtests than in the performance subtests of the Wechsler scales, contrasted with that found in comparable studies of detoxified adult alcoholics ${ }^{26} 27$ and children with definite brain injury due to a variety of causes, ${ }^{28} 29$ in which impairment has usually been greater on the performance scale.

The one finding that suggested a causal effect of volatile substance abuse on neuropsychological functioning was the apparent deterioration in the test scores of the index children relative to their scores before their first episode of sniffing. In theory, longitudinal evidence of this kind should provide a strong test of the causal hypothesis. The interpretation of these data, however, is complicated by several considerations. Firstly, data from antecedent tests. were obtained for only half of the matched pairs. Secondly, the data that were obtained came from a variety of tests, none of which was identical with those used during the course of the study. Thirdly, the coherence of these data is questionable inasmuch as the antecedent verbal reasoning scores of the index children were higher than those of the controls and the observed deterioration in scores reflected a fall from an unexplained superior performance to roughly normal. In view of these considerations the possibility of deterioration must remain just a possibility.

Taken together, the findings of our study provide only limited support for the idea that volatile substance abuse causes neuropsychological impairment, the bulk of the evidence going against this hypothesis. This conclusion might merely reflect the imperfect sensitivity of the tests used to detect impairment. Similar batteries of tests, however, have shown acute impairment in laboratory studies of volunteers exposed to comparatively low concentrations of solvents and persistent deficits in clinical groups such as adult alcoholics ${ }^{1727}$ and children with various forms of brain damage in whom comparable questions concerning impairment have been raised. ${ }^{29}$

Alternatively, the findings may underestimate the magnitude of impairment attributable to volatile substance abuse because pupils who were absent from school on the day the questionnaire was given were not included in the sample. Absentees from school include a disproportionate number of drug users, ${ }^{30}$ and frequent drug users are particularly likely to be absent on any given day. To some extent, however, we redressed the resulting underrepresentation of frequent abusers by preferentially selecting pupils who acknowledged frequent abuse. Though we cannot say whether the frequency of abuse in our selected children precisely reflects the frequency of the practice in the combined population of children attending and absent from the schools, we believe that it was probably not very different. Despite the strong association between absenteeism and drug abuse only a minority of absentees abuse drugs and probably only a minority of this minority are frequent drug users.

Nevertheless, emphasising the limits of generalising the present findings is important. The pattern of abuse among the index children we studied could best be described as predominantly experimental or occasional with only a minority reporting frequent or habitual abuse. Our findings cannot necessarily be generalised to children whose abuse is more frequent or prolonged or to those who have abused different products. Similarly, it would be wrong to infer from our findings that occasional volatile substance abuse is harmless. At least $10 \%$ of 13-16 year old children whose deaths were associated with abuse were abusing for the first time (H R Anderson et al, unpublished data). Nevertheless, our finding that volatile substance abuse as commonly practised by secondary school pupils is unlikely to result in neuropsychological impairment is reassuring. This should contribute to the informed clinical assessment of adolescents who present with a history of occasional solvent abuse as well as to the counselling of those young people and parents who are unduly worried about the damage that may have been done.

We thank Corrine Moy, Simon Walker, Stephen Bailey, Clare Byrne, and Andrew Tickle for help with the fieldwork; Professor Andrew Mathews for constructive advice; and the staff and pupils of the participating schools. The work was supported by a grant from the Department of Health and Social Security.

\footnotetext{
Watson JM. Solvent abuse: the adolescent epidemic? London: Croom Helm, 1986.

Swadi H. Drug and substance abuse among 3333 London adolescents. Br $\mathcal{F}$ Addict 1988;83:935-42.

3 Cooke BRB, Evans DA, Farrow SC. Solvent misuse in secondary school children - a prevalence study. Community Med 1988;10:8-13.

4 Gamberale F. Behavioral effects of exposure to solvent vapors: experimental and field studies. In: Horvath $M$, ed. Adverse effects of environmental chemicals and psychotropic drugs. Amsterdam: Elsevier, 1976:111-33.

5 Cherry N, Waldron HA, eds. The neuropsychological effects of solvent exposure. Havant, Hampshire: Colt Foundation, 1983.

6 Ron MA. Volatile substance abuse: a review of possible long-term neurological, intellectual and psychiatric sequelae. Br f P Psychiatry 1986;148:235-46.

7 Fornazzari L, Wilkinson DA, Kapur BM, Carlen PL. Cerebellar, cortical and
} 
functional imparment in toluene abusers. Acta Neurol Scand 1983;67: 319-29.

8 Lolin Y. Chronic neurological toxicity from volatile substances of abuse. Hum Toxicol (in press).

9 Chadwick OFD, Anderson HR. Neuropsychological consequences of volatile substance abuse: a review. Hum Toxicol (in press).

10 Plant MA, Peck DF, Samuel E. Alcohol, drugs and school-leavers. London: Tavistock, 1985

11 Johnson LD, O'Malley PM, Bachman JG. Drugs and American high school students: 1975-1983. Rockville, Maryland: National Institute on Drug students: $1975-1983$. Rockville, Maryland: National Institute on Drug

12 Kandel D, Single E, Kessler RC. The epidemiology of drug use among New York State high school students: distribution, trends and changes in rates of use. Am F Public Health 1976;66:43-53.

13 Wechsler D. Wechsler intelligence scale for children-revised. New York: Psychological Corporation, 1974

14 Bate SM. Reading test $E H-3$. Windsor, Berkshire: National Foundation for Educational Research, 1970.

15 Wechsler D. A standardised memory scale for clinical use. $f$ Psychol 1945;19:87-95

16 Elliot C, Murray DJ, Pearson LS. The British ability scales. Windsor, Berkshire: National Foundation for Educational Research, 1983.

17 Acker W, Acker C. The Bexley-Maudsley automated psychological screening test. Windsor, Berkshire: National Foundation for Educational test. Windsor, Berch-Nelson, 1982.

18 Armitage SG. An analysis of certain psychological tests used for the evaluation of brain injury. Psychological Monographs 1946;60:1-48. (No 277.)

19 Annett M. The growth of manual preference and speed. Br $\mathcal{F}$ Psychol Annett M. The g
1970;61:545-58.
20 Bloom S, Till S, Sönksen P, Smith S. Use of a biothesiometer to measure individual vibration thresholds in 519 non-diabetic subjects. Br Med $\mathcal{J}$ 1984;288:1793-5.

21 Anonymous. London reading test: teacher's manual. Windsor, Berkshire: Inner London Education Authority and National Foundation for Educational Research-Nelson, 1980 (table 5)

22 Knave B, Olson BA, Elofsson A, et al. Long-term exposure to jet fuel: cross-sectional epidemiologic investigation on occupationally exposed industrial workers with special reference to the nervous system. Scand $\mathcal{F}$ Work Environ Health 1978;4:19-45.

23 Wechsler D. The measurement and appraisal of adult intelligence. 4th ed. Baltimore: Williams and Wilkins, 1958.

24 Douglas VI. Attentional and cognitive problems. In: Rutter M, ed Developmental neuropsychiatry. New York: Guilford, 1983:280-329.

25 Lishman AW. Organic psychiatry. 2nd ed. Oxford: Blackwell, 1987.

26 Tarter RE. Psychological deficits in chronic alcoholics: a review. Int $\mathcal{F}$ Addic 1975;10:327-68.

27 Ron MA. Brain damage in chronic alcoholism: a neuropathological, neuroradiological and psychological review. Psychol Med 1977;7:103-12.

28 Rutter M, Graham P, Yule W. A neuropsychiatric study in childhood. London: Spastics International Medical Publications-Heinemann Medical Books, 1970. (Clinics in Developmental Medicine Nos 35-6.)

29 Chadwick O, Rutter M. Neuropsychological assessment. In: Rutter M, ed. Developmental neuropsychiatry. New York: Guilford, 1983:181-212.

30 Kandel D. Reaching the hard-to-reach: illicit drug use among high school absentees. Addictive Diseases 1975;1:465-80.

(Accepted 10 April 1989)

\title{
Inhibin: a new circulating marker of hydatidiform mole?
}

\author{
Takashi Yohkaichiya, Takao Fukaya, Hiroshi Hoshiai, Akira Yajima, David M de Kretser
}

\section{Abstract}

Objective-To define the concentrations of inhibin in serum and tissue of patients with hydatidiform mole and assess their value as a clinical marker of the condition.

Design-Prospective study of new patients with hydatidiform mole, comparison of paired observations, and case-control analysis.

Setting-A university hospital, two large public hospitals, and a private women's clinic in Japan.

Patients-Seven consecutive referred patients seen over four months with newly diagnosed complete hydatidiform mole, including one in whom the mole was accompanied by viable twin fetuses (case excluded from statistical analysis because of unique clinical features). All patients followed up for six months after evacuation of molar tissue.

End point-Correlation of serum inhibin concentrations with trophoblastic disease.

Measurements and main results-Serum concentrations of inhibin, human chorionic gonadotrophin, and follicle stimulating hormone were compared before and seven to 10 days after evacuation of the mole. Before evacuation the serum inhibin concentrations (median $8.3 \mathrm{U} / \mathrm{ml} ; 95 \%$ confidence interval 2.4 to 34.5 ) were significantly greater than in 21 normal women at the same stage of pregnancy $(2.8$ $\mathrm{U} / \mathrm{ml} ; 2 \cdot 1$ to $3 \cdot 6$ ), and inhibin in molar tissue was also present in high concentrations $(578 \mathrm{U} / \mathrm{ml}$ cytosol; 158 to 1162). Seven to 10 days after evacuation inhibin concentrations in serum samples from the same patients declined significantly to values $(0.4 \mathrm{U} / \mathrm{ml} ; 0.1$ to 1.4$)$ similar to those seen in the follicular phase of normal menstrual cycles. None of the four patients whose serum inhibin concentrations were $0.4 \mathrm{U} / \mathrm{ml}$ or less after evacuation developed persistent trophoblastic disease. Though serum human chorionic gonadotrophin concentrations declined after evacuation $\left(6.6 \times 10^{3} \mathrm{IU} / 1 ; 0.8 \times\right.$ $10^{3}$ to $\left.32.6 \times 10^{3}\right)$, they remained far higher than in non-pregnant women. Serum follicle stimulating hormone concentrations remained suppressed.

Conclusions - In this small study serum inhibin concentrations higher than those found in the early follicular phase one to two weeks after evacuation of a hydatidiform mole seemed to be specific for persistent trophoblastic disease. Further data are needed to confirm these promising results.

\section{Introduction}

Inhibin, a glycoprotein hormone produced by the testis and ovary, has the ability preferentially to suppress the secretion of follicle stimulating hormone by the pituitary. After its initial isolation from bovine follicular fluid ${ }^{1}$ we showed that inhibin was also produced by the placenta ${ }^{2}$ and that concentrations rose during early pregnancy. ${ }^{3}$ Other studies using immunocytochemistry have localised inhibin to the cytotrophoblast of the placenta, ${ }^{+}$which has been shown to contain messenger ribonucleic acid for the inhibin subunits. ${ }^{5}$ The production of inhibin by trophoblastic tissue and the availability of specific radioimmunoassays for inhibin prompted us to study the concentrations of inhibin in women with a gestational trophoblastic disease such as hydatidiform mole. This paper reports our results.

\section{Subjects and methods}

Serum and molar tissue were obtained from seven patients (median age 32 years, range 18-46) with hydatidiform mole managed at Tohoku University Hospital and its affiliated institutions. Diagnosis was based on the clinical symptoms, ultrasonic findings, laboratory data, and histological appearances of samples obtained at curettage. Gestational age at the time of primary evacuation was calculated from the date of the last menstrual period as a median of $12 \cdot 1$ weeks (range 9-17 weeks), and no patient had a previous history of gestational trophoblastic disease. All except one of the cases were diagnosed as complete hydatidiform mole without a fetus. In the exception (case 1) the hydatidiform mole coexisted with viable twin fetuses. This patient had been treated with human menopausal and human chorionic gonadotrophin for anovulation. Two months after diagnosis of the mole and despite prophylactic methotrexate one week after primary evacuation the patient had persistent trophoblastic disease. Because of the unique clinical features 